\title{
Mapping of QTL for Seed Size and Shape Traits in Common Bean
}

\author{
Soon O. Park and Dermot P. Coyne \\ Department of Horticulture, University of Nebraska, Lincoln, NE 68583 \\ Geunhwa Jung and Paul W. Skroch \\ Department of Horticulture, University of Wisconsin, Madison, WI 53706
}

E. Arnaud-Santana

Centro de Investigaciones Agricola del Surocate (CIAS), Apartado \#145, San Juan de la Maguana, Dominican Republic

James R. Steadman

Department of Plant Pathology, University of Nebraska, Lincoln, NE 68583

H.M. Ariyarathne

Department of Horticulture, University of Nebraska, Lincoln, NE 68583

James Nienhuis

Department of Horticulture, University of Wisconsin, Madison, WI 53706

\begin{abstract}
ADDitional INDEX wORDs. Phaseolus vulgaris, recombinant inbred lines, randomly amplified polymorphic DNA markers, quantitative trait loci, common bacterial blight resistance
\end{abstract}

\begin{abstract}
Our objective was to identify quantitative trait loci (QTL) for seed weight, length, and height segregating in a recombinant inbred line population derived from the common bean (Phaseolus vulgaris L.) cross 'PC-50' X XAN-159. The parents and progeny were grown in two separate greenhouse experiments in Nebraska, and in field plots in the Dominican Republic and Wisconsin. Data analysis was done for individual environments separately and on the mean over all environments. A simple linear regression analysis of all data indicated that most QTL appeared to be detected in the mean environment. Based on these results, composite interval mapping (CIM) analysis was applied to the means over environments. For seed weight, strong evidence was indicated for five QTL on common bean linkage groups (LGs) 3, 4, 6, 7, and 8. Multiple regression analysis (MRA) indicated that these QTL explained $44 \%$ of the phenotypic variation for the trait. Weaker evidence was found for three additional candidate QTL on bean LGs 4, 5, and 8. All eight markers associated with these QTL were significant in a MRA where the full model explained $63 \%$ of the variation among seed weight means. For seed length, CIM results indicated strong evidence for three QTL on LG 8 and one on LG 2. Three additional putative QTL were detected on LGs 3, 4, and 11. The markers associated with the three seed length QTL on LG 8, and the QTL on LGs 2 and 11 were significant in a MRA with the full model explaining $48 \%$ of the variation among seed length means. For seed height, three QTL on LGs 4, 6, and 11 explained 36\% of the phenotypic variation for trait means. Four of the seven QTL for seed length and two of three QTL for seed height also appeared to correspond to QTL for seed weight. Four QTL for common bacterial blight resistance [Xanthomonas campestris pv. phaseoli (Smith Dye)] and for smaller seed size were associated on LGs 6, 7, and 8. The implications of these findings for breeders is discussed.
\end{abstract}

Common bean (Phaseolus vulgaris) is an important economic food legume and is widely grown in North, Middle and South America, Eastern Africa, Europe, and China (Pachico, 1989). The bean seed is rich in protein, fiber, carbohydrates, minerals, and vitamins. Beans provide a good source of protein for rural and urban poor in many developing countries (Pachico, 1989).

Bean seed weight and shape are important traits of different market bean classes. The former is also an important component of yield (Al-Mukhtar and Coyne, 1981; Conti, 1982, 1985). Bean seed weight has been negatively correlated with yield (White and Gonzalez, 1990; White et al., 1992), relative growth rate (Laing et al., 1984; White et al., 1992), number of pods per plant (Coyne,

Received for publication 27 July 1998. Accepted for publication 21 Feb. 2000 Published as Nebraska Agricultural Research Division journal series paper 12166. Research was conducted under Projects 20-036 and 20-042. We acknowledge financial support from the Title XII Bean/Cowpea CRSP (AID Contract No. DNA-1310-G-SS-6008-00). We also appreciate assistance of Lisa Sutton and James Reiser. The cost of publishing this paper was defrayed in part by the payment of page charges. Under postal regulations, this paper therefore must be hereby marked advertisement solely to indicate this fact.
1968), number of seeds per pod (Coyne, 1968), and biomass (White et al., 1992). Seed weight has been found to be positively correlated with cell size of different tissues (White and Gonzalez, 1990). Quantitative inheritance patterns of seed weight were reported by several investigators (Coyne, 1968; Motto et al., 1978; Nienhuis and Singh, 1988; Sax, 1923; Vallejos and Chase, 1991; Yarnell, 1965). Quantitative inheritance patterns of some determinants of bean seed shape such as seed length, seed width, and seed height were reported by Vallejos and Chase (1991). Singh (1991) indicated that narrow-sense heritability $\left(h^{2}\right)$ for seed size ranged from 0.56 to 0.81 . Conti (1985) reported $h^{2}$ for seed length (0.09), seed thickness (0.47), and seed width (0.65).

One of the first associations found between a genetic marker and a quantitative trait was reported by Sax (1923) for the relationship between seed pigmentation $(P$ gene $)$ and seed weight in common bean. More recently three types of molecular markers have been used to study the genetics of seed weight in common bean including isozyme (Vallejos and Chase, 1991; Vallejos et al., 1992), restriction fragment length polymorphism (RFLP) (Koinange et al., 1996; Nodari, 1992) and seed protein markers 
(Delaney and Bliss, 1991; Hartana, 1983; Johnson et al., 1996; Koinange et al., 1996; Nodari, 1992). Isozyme markers have also been used to study the genetics of seed length and seed height by Vallejos and Chase (1991) and Vallejos et al., (1992). These studies have contributed to our understanding of the genetics of seed size and shape and offer prospects for the use of molecular markers in the modification or maintenance of seed characteristics in bean breeding programs.

In a molecular marker based analysis, Jung et al. (1997) used randomly amplified polymorphic DNA (RAPD) markers to identify and map quantitative trait loci (QTL) for resistance to common bacterial blight (CBB), caused by Xanthomonas campestris pv. phaseoli. In a subsequent study the same population was used to map genes for specific resistance (Ur-9) and adult plant resistance $(U r-12)$ to rust, and abaxial leaf pubescence (Pu-a) (Jung et al., 1998). Our objective in the current study was to use this previously studied population to identify QTL associated with seed weight, length, and height. Through collection of phenotypic data in different environments we were also able to evaluate the consistency of significant marker locus-trait associations across environments, and relative to the mean environment. Finally, the integrated bean genetic map was used to compare the locations of QTL identified in this study with previously detected QTL for seed traits in other populations.

\section{Materials and Methods}

Plant materials. Recombinant inbred lines (RILs) derived from the cross 'PC-50' $x$ XAN-159 were developed using singleseed descent (Arnaud-Santana et al., 1994). 'PC-50' was derived from a single plant selection in the landrace 'Pompadour Checa' in the Dominican Republic (Saladin et al., 1999). XAN-159 was derived from interspecific crosses between $P$. vulgaris and $P$. acutifolius A. Gray accession PI 319443 to introduce CBB resistance genes into the common bean genomic background (Thomas and Waines, 1984). 'PC-50' is from the Andean gene pool (Singh et al., 1991a). XAN-159 has a predominately Andean genetic background despite having a mixed pedigree (Johns et al., 1997). Major characteristics of two parents are indicated in Table 1.

Sixty-three RILs and parents were planted in a randomized complete block design (RCBD) with three replications in the greenhouse in Lincoln, Nebr. on 3 May 1995 (Expt. 1) and 9 Nov. 1996 (Expt. 2). Seven RILs in each experiment were not planted because of lack of seeds. Two plants were grown per clay pot, volume $1450 \mathrm{~cm}^{3}$, containing equal parts of sand, sphagnum peat moss, vermiculite, and sharpsburg silty clay loam soil. Peters 20N-10P-20K Peat-Lite Special (Scotts-Sierra Horticultural Products Co., Marysville, Ohio) water soluble fertilizer was applied weekly. The chemical Orthene 75 s soluble powder (active ingredient Acephate; O,S-dimethyl acetyl-phosphophoramidothioate) (Valent Co., Walnutcreek, Calif.) was applied weekly to control white flies. Approximate day/night greenhouse temperatures were $28 \pm 3 / 23 \pm 3{ }^{\circ} \mathrm{C}$ in Expt. 1 and $27 \pm 2 / 22 \pm 2$ ${ }^{\circ} \mathrm{C}$ in Expt. 2. Lengths of natural days/nights ranged from $15 / 9 \mathrm{~h}$ in Expt. 1 and 10/14 h in Expt. 2.

For Expt. 3, the parents and 64RILs were planted in a RCBD with four replications on 15 Jan. 1997 in the field in San Juan de la Maguana, Dominican Republic. A fertilizer containing $16 \mathrm{~N}-18 \mathrm{P}-5 \mathrm{~K}$ was applied to the plot area at the rates of 76,85 , and $24 \mathrm{~kg} \cdot \mathrm{ha}^{-1}$, respectively. Six RILs were not planted because of lack of seeds. Single row plots were $1.2 \mathrm{~m}$ long and spaced $0.5 \mathrm{~m}$ apart. Five to eight seeds of each line were planted 15 to $24 \mathrm{~cm}$ apart. Approximate day/night field temperatures were $27 \pm 2 / 22 \pm 2{ }^{\circ} \mathrm{C}$ and the lengths of natural days/nights ranged from 12 to $13 / 11$ to $12 \mathrm{~h}$. In Expt. 4, the parents and 65 RILs were planted in a RCBD with four replications on 15 June 1997 in the field in Hancock, Wisconsin. A fertilizer containing $5 \mathrm{~N}-10 \mathrm{P}-30 \mathrm{~K}$ was applied to the plot area at the rate of $45 \mathrm{~kg} \cdot \mathrm{ha}^{-1}$. Five RILs were not planted because of lack of seeds. Plot dimensions and seeding rates were identical to Expt. 3. Sprinkler irrigation was used to apply water as needed. Approximate day/night field temperatures were $33 \pm 3 / 22 \pm 3{ }^{\circ} \mathrm{C}$ and the lengths of natural days/nights ranged from 13 to $15 / 9$ to $11 \mathrm{~h}$.

Phenotypic Data. The weight in grams of 100 seeds per line was recorded in all experiments. Seed length was defined as the longest distance across the seed parallel to the hilum, and seed height as the longest distance from top to bottom of the seed. The width of the seed was not measured. Ten seeds per line were used to record seed length and seed height in centimeters in Expts. 1 and 2. Seed moisture content was 9.5\% in Expts. 1 and 2 and $13.5 \%$ in Expts. 3 and 4 at time of recording the data. An infra red reflectance analyzer (Infratec 1255 Food Analyzer) (Foss NIRS Systems, Silver Spring, Maryland) was used to determine moisture content of seed in Expts. 1 and 2. The moisture content of the seed of lines in Expt. 3 was determined using a Burrows Digital Moisture Computer, Model 700 (Seedburo Equipment Co., Chicago, Illinois). Seed moisture of lines in Expt. 4 was determined using oven dried seed to a constant seed weight.

LINKAGE MAP CONSTRUCTION. The RAPD marker-based linkage map was originally developed by Jung et al. (1997) using 70 RILs of the same cross. Subsequently, to facilitate integration of this map with other RAPD and RFLP maps in bean, the segregation data were reanalyzed by Skroch (1998) with some markers being added and some omitted from the different linkage groups (LGs). LG names were changed from Jung et al. (1997) to reflect their correspondence with the integrated common bean linkage map (Freyre et al., 1998; Vallejos et al., 1999). MAPMAKER Macintosh version 2.0(Lander

Table 1. A summary of selected characteristics of the two parents 'PC-50' and XAN-159 of Andean origin.

\begin{tabular}{lll}
\hline \hline Trait (allele) & PC-50 & XAN-159 \\
\hline Seed shape & Ovate & Flat rhomboidal \\
Seed weight & Larger & Smaller \\
Seed length & Shorter & Longer \\
Seed height & Greater & Lesser \\
Flower color & Pink $\left(v^{\text {lae }}\right)$ & Purple $(V)$ \\
Seedcoat pattern $(C)$ & Reddish marbled & Speckled rhomboidal striping with fine dotting \\
Common bacterial blight & Susceptible & Resistant \\
Rust & Specific resistance $(U r-9)$ & Susceptible \\
Abaxial leaf surface & Adult plant resistance $(U r-12)$ & Nearly glabrous \\
\hline
\end{tabular}



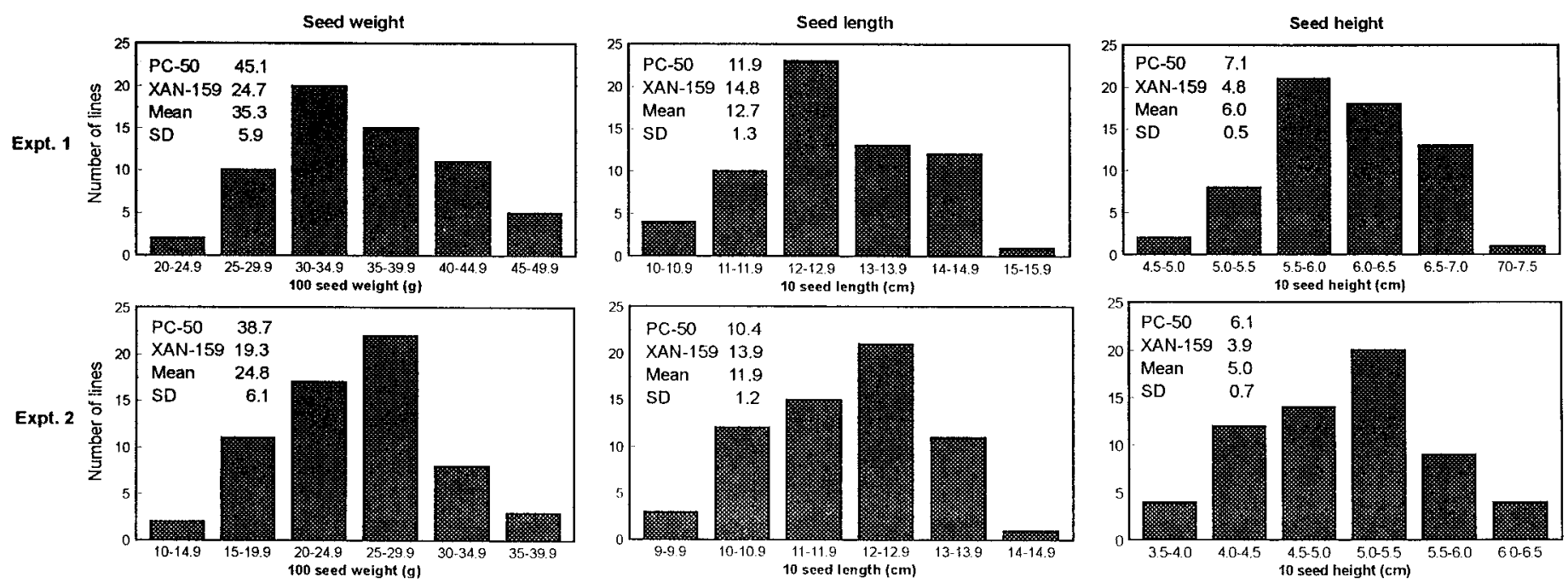
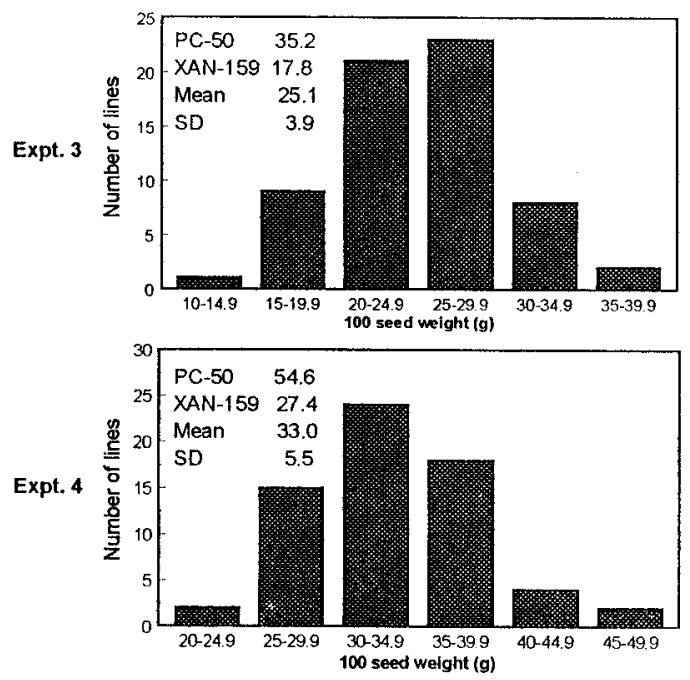

Fig. 1. Frequency distributions for seed weight (100 seeds/g), length $(\mathrm{cm})$, and height $(\mathrm{cm})$ of recombinant inbred lines derived from the cross 'PC-50' $\times$ XAN159.

et al., 1987) was used to order LGs. The modified linkage map spanned $404 \mathrm{cM}$ compared to $426 \mathrm{cM}$ in the original map reported by Jung et al. (1997). RAPD markers are designated by the letter identifying the Operon kit or a BC prefix, the primer number and the approximate length to the nearest 50 base pairs.

QTL Detection. Simple linear regression (SLR), for each pairwise combination of quantitative traits and marker loci, was used to analyze the data for detection of QTL affecting seed weight, length, and height for individual environments corresponding to Expts. 1 to 4, and the mean environment. Significant differences in trait associations were based on $\mathrm{F}$ tests $(P<0.05)$ (Edwards et al., 1987).

Composite interval mapping (CIM) analysis was applied to the trait means and marker data to more precisely identify the locations of QTL (Zeng, 1994). CIM analysis was performed using QTL Cartographer software (Basten et al., 1996) version $1.13 \mathrm{~g}$. Cofactors were chosen based on the results of a forward stepwise multiple regression analysis (MRA) using the QTL Cartographer program SRmapqtl (model 6). Output from SRmapqtl was used directly so the number of cofactors varied for each trait depending on the number of significant markers in the MRA results. A window size of $10 \mathrm{cM}$ was used. For direct comparison of QTL for seed traits with QTL for CBB resistance identified in a previous study (Jung et al., 1997), mean resistance measurements for first trifoliolate and later developed leaves to CBB strain EK11 were computed and CIM analysis was performed as for seed traits described above.

\section{Results}

Seed Trait Data. Continuous distributions for bean seed weight, length, and height were observed for RILs of the cross 'PC-50' $\times$ XAN-159 in all experiments (Fig. 1) indicating quantitative inheritance for the traits. Quantitative inheritance of bean seed weight has been reported previously many times (Coyne, 1968; Motto et al., 1978; Nienhuis and Singh, 1988; Sax, 1923; Vallejos and Chase, 1991; Yarnell, 1965). Frequency distributions for seed weight, length, and height in Expt. 2 and for seed weight and height in Expt. 1 were normal $(P=0.09$ to 0.82$)$, whereas frequency distributions for seed weight in Expts. 3 and 4 and for seed length in Expt. 1 deviated significantly $(P=0.01$ to 0.04 ) from normality. The data for seed weight in Expts. 3 and 4 and for seed length in Expt. 1 were normally distributed after transformation using the common log. However, when the transformed data were used for the detection of QTL the results were very similar to results based on the original data. Thus, for detection of QTL based on SLR the original data were used for all traits and experiments.

Correlations of traits measured in different experiments were high and significant in most cases. For seed weight, measured in four separate experiments, significant correlations were observed for all pairwise comparisons of experiments except for the winter greenhouse compared to the DR experiment ( $r=0.09, P=0.25)$. Phenotypic correlations for seed length and height compared across two greenhouse experiments were 0.49 and 0.60 , respectively. For all traits, measurements based on individual experiments were highly correlated with the means over experiments $(r$ $>0.60)$. Comparison of seed weight, length, and height based on the means over experiments indicated highly significant correlations of seed weight compared to seed height $(r=0.60)$ and length $(r=0.57)$ but a nonsignificant correlation between seed height and length $(r=0.10)$.

LINKAGE MAP INTEGRATION. A total of 10 LGs were identified. Based on the cosegregating markers used for construction of integrated RAPD-RFLP linkage maps these 10 LGs were consolidated to nine LGs spanning $404 \mathrm{cM}$ and correlated with LGs in the maps of Freyre et al. (1998) and Vallejos et al. (1999) (Fig. 
B2/D

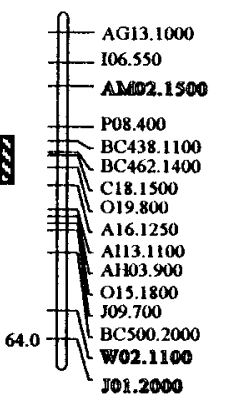

B7/A

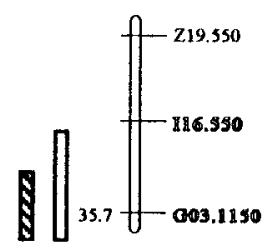

B8/F
B4/B
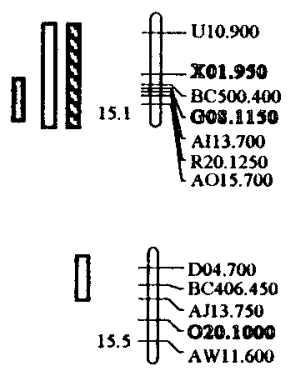

$\mathbf{B 5} / \mathbf{E}$

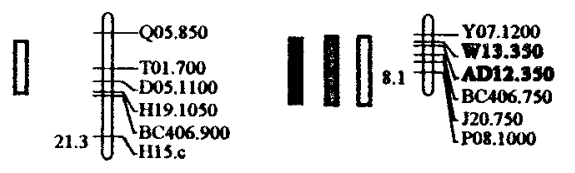

B6/G
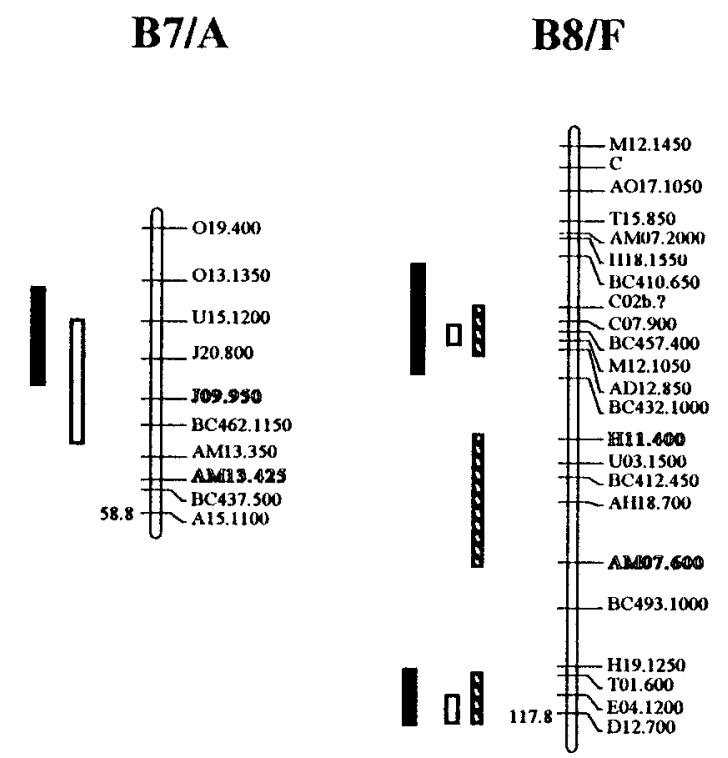

B10/I

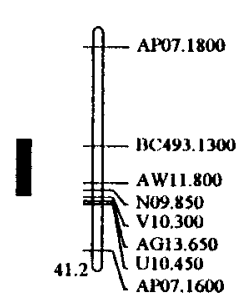

\section{B11/J}

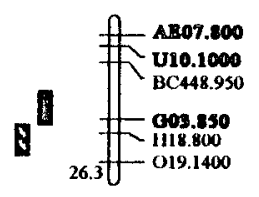

Seed length
Seed height
$\square$ Seed weight

Common bacterial blight resistance

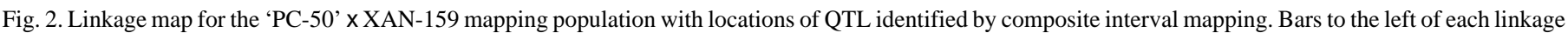

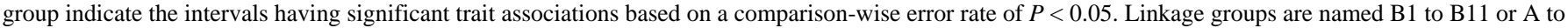

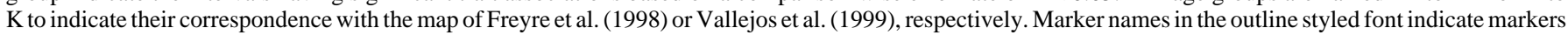
that were used directly in the integration of RFLP and RAPD maps by Freyre et al. (1998).

2). In this report LGs will be referenced using numbers 1 to 11 to refer to LGs B1 to B11 from Freyre et al. (1998). The correspondence of the LG names in the original 'PC-50' $x$ XAN-159 (PX) map with the LG names in the present report are PX2 $=2$, PX3 = 3, $\mathrm{PX} 6=4 \mathrm{a}, \mathrm{PX} 8=4 \mathrm{~b}, \mathrm{PX} 7=5, \mathrm{PX} 5=6, \mathrm{PX} 4=7, \mathrm{PX} 1=8, \mathrm{PX} 9$ $=10$, and PX10 $=11$ (Fig. 2). In addition to RAPD markers, the $C$ locus for seedcoat pattern was mapped previously to LG 8 (PX1), the $V$ locus for flower color (data not presented) was mapped previously to LG 6 (PX5), and the $P u$-a gene for abaxial leaf pubescence (data not presented) was mapped to LG 3 (PX3) (Jung et al., 1997; Jung et al., 1998). Mmbaga et al. (1996) reported that the $P u$-a contributed to race-nonspecific adult plant resistance to rust in common bean.

COMPARISON OF QTL DETECTION ACROSS ENVIRONMENTS. Seed weight was measured in four separate experiments corresponding to four distinct environments including summer (Expt. 1) and winter (Expt. 2) greenhouse environments in Nebraska as well as field environments in DR (Expt. 3) and Wisconsin (Expt. 4). Candidate seed weight QTL were identified by markers that were significantly associated with trait variation in at least two environments or the mean over environments (Table 2). A relatively large number of marker locus-trait associations were significant in a single environment. However, most of these (12/17) were only weakly significant $(0.01<P<0.05)$, not linked to markers for which there was stronger evidence of QTL associations $(P<$ 0.01 ), and not significantly associated with the mean over environments. Better evidence was found for five of these 17 loci $(P$ $<0.01)$ that were also significant for the mean over experiments. However, three of these were relatively closely linked to markers on LGs 3 and 7 where there was strong evidence $(P<0.001)$ of seed weight QTL. Thus, of the 17 markers significantly associated with seed weight in only one environment only two, BC432.1000 and BC493.1000 on LG 8, were significant for the mean over environments and were not closely linked to markers with a more significant association. When markers were significantly associated with trait variation in at least two environments all but one was also significant for the mean over environments. The only marker on LG 5 significantly associated with seed weight, Q05.850, was significantly associated with seed weight based on the mean over environments and not based on data from individual experiments.

In this study data were collected for seed length and height 
Table 2. RAPD marker loci significantly associated with seed weight in at least two environments or the mean over environments based on simple linear regression. $P$-values are given for 100 seed weight measured for plants grown in a summer greenhouse environment (Expt. 1), a winter greenhouse environment (Expt. 2), in the field in the Dominican Republic (Expt. 3), in the field in Hancock, Wisconsin (Expt. 4), and for the mean over environments.

\begin{tabular}{|c|c|c|c|c|c|c|c|}
\hline Marker & Linkage group ${ }^{2}$ & $P_{\text {Expt. } 1}$ & $P_{\text {Expt. 2 }}$ & $P_{\text {Expt. } 3}$ & $P_{\text {Expt. } 4}$ & $P_{\text {Mean }}$ & $R^{2 \mathrm{y}}$ \\
\hline $\mathrm{I} 16.550$ & 3 & 0.025 & 0.821 & 0.190 & 0.042 & 0.042 & 4.7 \\
\hline G03.1150 & 3 & 0.001 & 0.469 & 0.049 & 0.300 & 0.019 & 8.4 \\
\hline AO15.700 & $4 a$ & 0.008 & 0.043 & 0.042 & 0.042 & 0.001 & 14.9 \\
\hline G08.1150 & $4 a$ & 0.003 & 0.050 & 0.002 & 0.025 & 0.000 & 22.8 \\
\hline U10.900 & $4 a$ & 0.106 & 0.554 & 0.070 & 0.013 & 0.019 & 8.3 \\
\hline Q05.850 & 5 & 0.441 & 0.137 & 0.086 & 0.092 & 0.045 & 5.3 \\
\hline Y07.1200 & 6 & 0.006 & 0.003 & 0.005 & 0.190 & 0.001 & 15.9 \\
\hline P08.1000 & 6 & 0.000 & 0.078 & 0.002 & 0.177 & 0.001 & 15.4 \\
\hline $\mathrm{J} 20.800$ & 7 & 0.124 & 0.555 & 0.218 & 0.006 & 0.029 & 7.3 \\
\hline J09.950 & 7 & 0.542 & 0.605 & 0.053 & 0.002 & 0.038 & 6.6 \\
\hline AM13.350 & 7 & 0.503 & 0.249 & 0.019 & 0.001 & 0.010 & 10.0 \\
\hline AM13.425 & 7 & 0.067 & 0.060 & 0.010 & 0.001 & 0.001 & 17.3 \\
\hline A15.1100 & 7 & 0.060 & 0.308 & 0.007 & 0.003 & 0.003 & 14.1 \\
\hline BC432.1000 & 8 & 0.014 & 0.102 & 0.155 & 0.499 & 0.034 & 6.9 \\
\hline BC493.1000 & 8 & 0.004 & 0.230 & 0.163 & 0.337 & 0.032 & 8.8 \\
\hline
\end{tabular}

The assigned number for the linkage group of marker as defined in Fig. 2.

yThe percentage of phenotypic variation explained by the markers based on simple linear regression and the mean over experiments.

from plants grown in two separate experiments conducted in two different greenhouse environments. For seed length 12 significant marker locus-trait associations were detected based on SLR (Table 3). Of these only two were significant in both experiments, however, nine of 12 were significant for the means over experiments. On LG 8 the $C$ locus and RAPD markers AO17.1050 and T15.850 were each significant in only one experiment but were all linked to marker H18.1550, which was significant in Expt. 1 and the mean. Two of the three linked markers in the interval C07.900 BC432.1000 were significant in only one experiment but BC457.400 was significant in both experiments and the mean. The linked markers in the interval T01.600-D12.700 on LG 8 were only significant in one experiment but were all significant for the mean. On LG 11 the significant marker H18.800 which was significant in the second experiment but not the first was closely linked to marker O19.1400 which was significant in both environments and the mean. The results suggest one seed length QTL in the interval $C-\mathrm{BC} 432.1000$ and a second QTL in the interval T01.600-D12.700 on LG 8, and one QTL on LG 11.
For seed height, a total of 19 significant marker locus-trait associations were detected using SLR analysis (Table 4). Of these 16 and seven significant associations were detected based on Expts. 1 and 2, respectively. Although only five markers were significant in both experiments, 14 of the 19 significant marker locus-trait associations were significant based on the mean over experiments. Two marker loci, P08.400 and U10.900, that were not significant in the mean environment were relatively highly significant in one environment $(P<0.01)$ and very nonsignificant in the other environment $(P>0.5)$. However, $\mathrm{P} 08.400$ was linked to a marker that was significant in the mean environment and U10.900 was linked to markers that were highly significant in both environments. Two other markers, W02.1100 and BC493.1000, were only weakly significant in one environment and not significant in the other. These two associations are likely either false positives or represent minor effects that don't consistently reach the level of statistical significance.

COMPOSITE INTERVAL MAPPING BASED ON QTL IDENTIFICATION. Based on the results from the SLR analysis, CIM analysis was

Table 3. RAPD marker loci and seedcoat pattern $(C)$ significantly associated with seed length based on simple linear regression. $P$ values are given for seed length measured in a summer greenhouse environment (Expt. 1) and a winter greenhouse environment (Expt. 2), and as the mean over environments.

\begin{tabular}{|c|c|c|c|c|c|}
\hline RAPD marker & Linkage group ${ }^{2}$ & $P_{\text {Expt. } 1}$ & $P_{\text {Expt. } 2}$ & $P_{\text {Mean }}$ & $R^{2 y}$ \\
\hline $\bar{C}$ & 8 & 0.282 & 0.030 & 0.112 & 3.4 \\
\hline AO17.1050 & 8 & 0.424 & 0.040 & 0.168 & 3.4 \\
\hline $\mathrm{T} 15.850$ & 8 & 0.085 & 0.011 & 0.029 & 7.3 \\
\hline H18.1550 & 8 & 0.026 & 0.070 & 0.049 & 6.0 \\
\hline C07.900 & 8 & 0.066 & 0.045 & 0.050 & 6.1 \\
\hline BC457.400 & 8 & 0.007 & 0.024 & 0.010 & 10.4 \\
\hline BC432.1000 & 8 & 0.027 & 0.562 & 0.045 & 6.4 \\
\hline Т01.600 & 8 & 0.031 & 0.862 & 0.036 & 8.6 \\
\hline E04.1200 & 8 & 0.001 & 0.239 & 0.001 & 15.4 \\
\hline D12.700 & 8 & 0.004 & 0.311 & 0.006 & 11.7 \\
\hline O19.1400 & 11 & 0.035 & 0.044 & 0.020 & 11.2 \\
\hline H18.800 & 11 & 0.733 & 0.039 & 0.194 & 2.9 \\
\hline
\end{tabular}

zThe assigned number for the linkage group of marker as defined in Fig. 2.

yThe percentage of phenotypic variation explained by the markers based on simple linear regression and the mean over experiments. 
Table 4. RAPD marker loci significantly associated with seed height based on simple linear regression. $P$ values are given for seed height measured in a summer greenhouse environment (Expt. 1) and a winter greenhouse environment (Expt. 2), and as the mean over environments.

\begin{tabular}{|c|c|c|c|c|c|}
\hline RAPD marker & Linkage group ${ }^{2}$ & $P_{\text {Expt. 1 }}$ & $P_{\text {Expt. 2 }}$ & $P_{\text {Mean }}$ & $R^{2 \mathrm{y}}$ \\
\hline P08.400 & 2 & 0.014 & 0.604 & 0.177 & 3.0 \\
\hline BC438.1100 & 2 & 0.021 & 0.670 & 0.211 & 3.1 \\
\hline W02.1100 & 2 & 0.040 & 0.340 & 0.151 & 2.5 \\
\hline I16.550 & 3 & 0.081 & 0.025 & 0.030 & 7.4 \\
\hline AO15.700 & $4 a$ & 0.000 & 0.051 & 0.002 & 14.6 \\
\hline AI13.700 & $4 a$ & 0.000 & 0.065 & 0.002 & 14.4 \\
\hline G08.1150 & $4 a$ & 0.000 & 0.053 & 0.002 & 16.4 \\
\hline BC500.400 & $4 a$ & 0.000 & 0.075 & 0.002 & 13.7 \\
\hline X01.950 & $4 a$ & 0.002 & 0.254 & 0.019 & 8.7 \\
\hline U10.900 & $4 a$ & 0.003 & 0.668 & 0.064 & 5.5 \\
\hline Y07.1200 & 6 & 0.044 & 0.002 & 0.005 & 12.0 \\
\hline W13.350 & 6 & 0.010 & 0.003 & 0.003 & 13.6 \\
\hline AD12.350 & 6 & 0.188 & 0.038 & 0.035 & 13.5 \\
\hline BC406.750 & 6 & 0.002 & 0.003 & 0.001 & 15.9 \\
\hline J20.750 & 6 & 0.000 & 0.002 & 0.000 & 18.9 \\
\hline P08.1000 & 6 & 0.000 & 0.006 & 0.001 & 17.1 \\
\hline BC493.1000 & 8 & 0.043 & 0.232 & 0.118 & 3.7 \\
\hline H18.800 & 11 & 0.063 & 0.109 & 0.045 & 6.2 \\
\hline G03.850 & 11 & 0.031 & 0.100 & 0.030 & 7.5 \\
\hline
\end{tabular}

zThe assigned number for the linkage group of marker as defined in Fig. 2.

yThe percentage of phenotypic variation explained by the markers based on simple linear regression and the mean over experiments.

applied to the trait means over environments. CIM results indicated evidence for seed weight QTL on LGs 3, 4, 6, 7, and 8 that exceeded both the comparison-wise and genome-wise significance thresholds $(P<0.05)$ (Table 5) (Fig. 3). Two additional QTL were suggested at marker loci BC406.450 and Q05.850 by relatively low comparison-wise $(P<0.01)$ and genome-wise $(P$ $<0.25) P$ values on LGs 4 and 5, respectively. Weak evidence was indicated for an additional seed weight QTL on LG 8 at marker locus BC457.400. Based on the MRA the five most significant regions accounted for $48 \%$ of the phenotypic variation for the trait. When the full model was fit, including all eight marker loci, all markers were significant $(P<0.05)$ with a total $R^{2}$ of 0.63 .

Compared to the SLR analysis, CIM results indicated seed weight QTL in approximately the same locations for LGs 3, 5, and

Table 5. Summary of results from composite interval mapping analysis of marker and trait data for detection of QTL associated with seed weight, length, and height in the 'PC-50' x XAN-159 recombinant inbred line population.

\begin{tabular}{|c|c|c|c|c|c|c|c|c|}
\hline Trait & Position & $\mathrm{LG}^{\mathrm{z}}$ & $\mathrm{LR}^{\mathrm{y}}$ & $P C^{\mathrm{x}}$ & $P G^{\mathrm{w}}$ & $A^{v}$ & $R^{2} \mathrm{SLR}^{\mathrm{u}}$ & $R^{2} \mathrm{MRA}^{\mathrm{t}}$ \\
\hline \multirow[t]{8}{*}{ Seed weight } & BC500.400 & $4 a$ & 28.4 & 0.000 & 0.000 & 1.62 & 17.1 & 18 \\
\hline & Q05.850 & 5 & 10.3 & 0.005 & 0.230 & 0.89 & 5.3 & 10 \\
\hline & Y07.1200 & 6 & 22.9 & 0.000 & 0.002 & 1.73 & 15.9 & 9 \\
\hline & G03.1150 & 3 & 18.0 & 0.000 & 0.017 & 1.58 & 8.4 & 9 \\
\hline & D12.700 & 8 & 15.4 & 0.000 & 0.038 & 0.73 & 3.5 & 5 \\
\hline & J09.950- 1.0 & 7 & 15.9 & 0.000 & 0.030 & 1.00 & 6.6 & 3 \\
\hline & BC406.450 & $4 b$ & 10.4 & 0.002 & 0.224 & 0.53 & 1.5 & 5 \\
\hline & BC457.400 & 8 & 4.7 & 0.043 & 0.916 & -0.78 & 4.0 & 4 \\
\hline \multirow[t]{7}{*}{ Seed length } & BC457.400 & 8 & 29.2 & 0.000 & 0.000 & -0.36 & 10.0 & 11 \\
\hline & $\mathrm{AH} 18.700+2.0$ & 8 & 27.0 & 0.000 & 0.000 & 0.20 & 3.3 & 14 \\
\hline & P08.400 & 2 & 18.9 & 0.000 & 0.006 & -0.21 & 3.7 & 12 \\
\hline & D12.700 & 8 & 21.8 & 0.000 & 0.002 & 0.38 & 11.7 & 6 \\
\hline & $\mathrm{H} 18.800+1.0$ & 11 & 11.6 & 0.003 & 0.142 & -0.20 & 2.7 & 5 \\
\hline & G03.1150- 5.6 & 3 & 7.2 & 0.018 & 0.576 & 0.18 & 2.4 & --- \\
\hline & G08.1150 & $4 a$ & 11.9 & 0.002 & 0.119 & 0.17 & 2.4 & --- \\
\hline \multirow[t]{3}{*}{ Seed height } & G08.1150 & $4 a$ & 12.1 & 0.001 & 0.067 & 0.21 & 16.4 & 16 \\
\hline & BC406.750 & 6 & 15.0 & 0.001 & 0.021 & 0.22 & 16.0 & 14 \\
\hline & $\mathrm{G} 03.850+3.0$ & 11 & 4.0 & 0.040 & 0.896 & 0.15 & 7.5 & 6 \\
\hline
\end{tabular}

${ }^{{ }_{\mathrm{LGG}}}=$ linkage group, the assigned number for the linkage group of marker as defined in Fig. 2.

${ }^{y}$ Likelihood ratio.

${ }^{\mathrm{x}}$ Comparison-wise $P$ value.

${ }^{\text {w }}$ Genome-wise $P$ value.

vThe additive effect associated with the PC-50 allele, based on the simple linear regression analysis at the nearest marker locus.

uThe percentage of phenotypic variation explained by the marker most closely linked to the QTL, based on simple linear regression (SLR).

tPercentage of phenotypic variation explained by marker loci based on multiple regression analysis (MRA). 

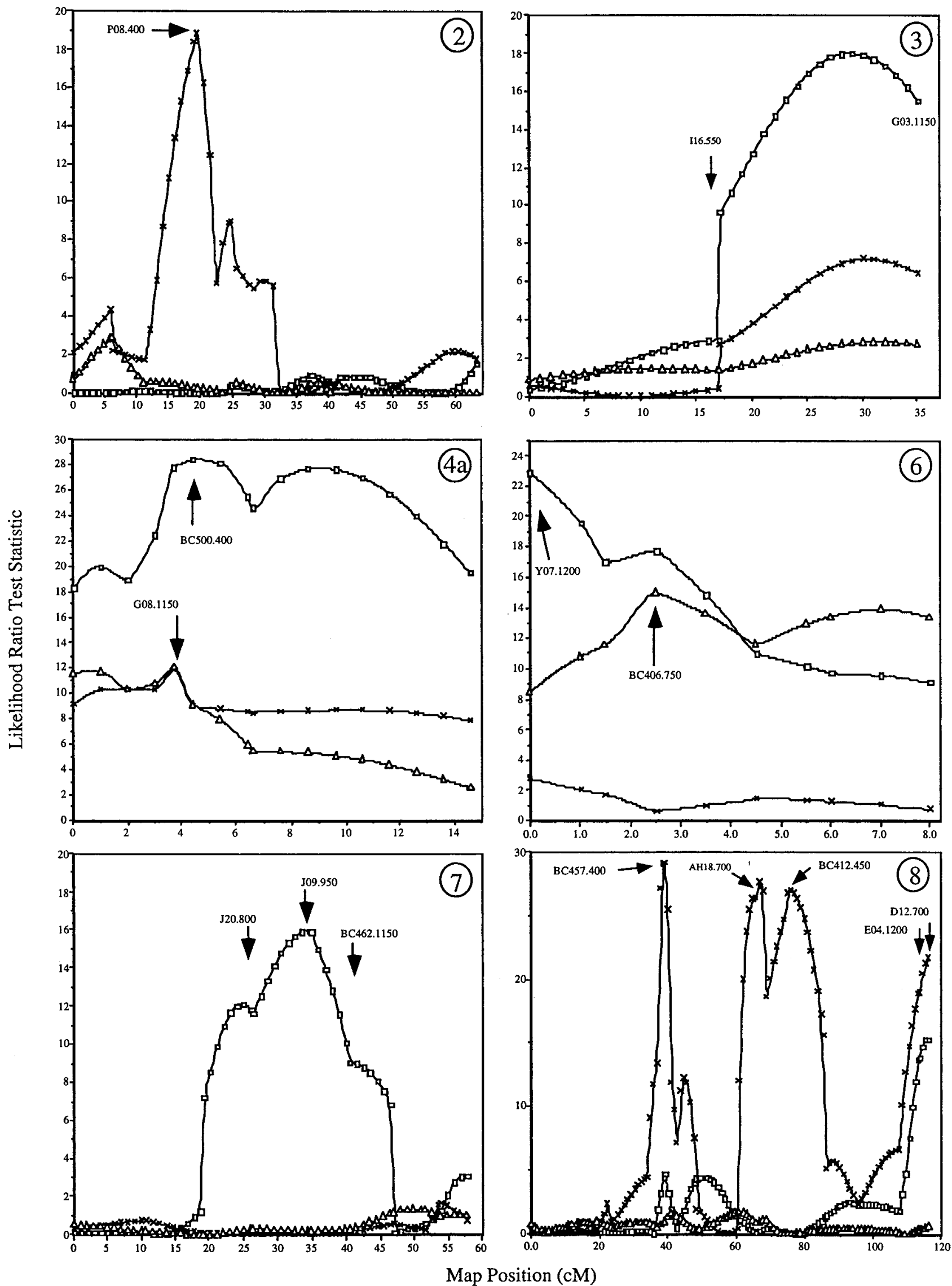

Fig. 3. Composite interval mapping results for seed weight (squares), length (crosses), and height (triangles). Plots of the likelihood ratio test statistic is shown for linkage groups 2, 3, 4a, 6, 7, and 8 corresponding to B2 to B8 in Fig. 2. The vertical axis of each plot specifies the likelihood ratio test statistic and the horizontal axis specifies distance along each of the linkage groups in $\mathrm{cM}$. 
6 as well as one of the QTL on LGs 4 (G08.1150) and 8 (BC457.400). Discrepancies in the most likely position occurred for QTL on LGs 7 and 8. On LG 7 the SLR analysis indicated a most likely position at marker AM13.425, $18 \mathrm{cM}$ from the CIM peak for that LG. On LG 8 the CIM peak was at marker locus D12.700, $23 \mathrm{cM}$ distal to marker BC493.1000. In addition, the significance level of the candidate QTL at marker locus D12.700 by CIM was much higher ( $P=0.000$ compared to 0.032$)$ than the association found by SLR for marker BC493.1000.

For seed length, candidate QTL $(P \mathrm{c}<0.05)$ were identified on LGs 2, 3, 4, 8, and 11 (Table 5) (Fig. 3). QTL linked to markers P08.400, BC457.400, AH18.700, and D12.700 were also significant based on genome-wise significance threshold. When entered into a stepwise MRA, the multilocus model containing these four markers and marker H18.800 explained $48 \%$ of the phenotypic variation for seed length. Markers G03.1150 and G08.1150 were not significant in the MRA.

Some differences were apparent when the SLR results for seed length were compared with those based on CIM. The minor effects identified using CIM on LGs 2, 3, and 4 were completely missed by the SLR analysis. There was strong evidence for a seed length QTL on LG 2 by CIM that was not identified using SLR. The SLR results for LG 8 suggested two independent QTL at marker BC457.400 and E04.1200. However, CIM results indicated the presence of three QTL, all highly significant on a genome-wise basis, near marker loci BC457.400, AH18.700, and D12.700. Although the SLR analysis indicated no markers in the region of AH18.700 on LG 8 which were significantly associated with seed length, the CIM analysis revealed a relatively small but highly significant effect in this region between the two major QTL for seed length at opposite ends of this LG.

For seed height the CIM analysis appears to have been less sensitive then the SLR analysis for QTL identification. One possibility was that this was due to the smaller number of cofactors used in the analysis for seed height (three compared to nine and 12 for seed length and seed weight, respectively). However, expanding the set of cofactors beyond the three picked using stepwise regression did not increase the sensitivity of the CIM analysis for detection of seed height QTL. Candidate QTL were identified on LGs 4, 6, and 11. All three markers identified by CIM were significantly associated previously with seed height based on SLR. However, no QTL for seed height were detected on LGs 8 and 11 as suggested by the SLR results. These three markers were significant in the MRA with the multilocus model explaining $36 \%$ of the phenotypic variation for the trait (Table 5).

\section{Discussion}

Overall, for seed length and height about $75 \%$ of all statistically significant marker locus-trait associations were found based on the means over environments. For seed weight, if marker locus-trait associations found in only one environment are excluded, more than $90 \%$ of significant marker locus trait associations were found for the mean over environments. Thus, although environmentally specific or environmentally enhanced QTL expression associated with some markers is suggested, most of these effects were detected using the trait means. Those significant associations that were not detected for the means appear to represent either type I errors or relatively minor effects. The results suggest that the best candidate QTL can be found using the trait means over environments. This conclusion is consistent with that of other studies that have evaluated mapping populations in multiple environments or years, and ultimately based QTL detection on the means over environments (Bohn et al., 1996; Veldboom and Lee, 1996) or years (Bohn et al., 1997). However, other researchers have preferred to evaluate results based on different environments separately (Byrne et al., 1998; Ribaut et al., 1997) emphasizing the existence of environmentally specific QTL as well as those QTL observed consistently across environments.

The $P$ locus associated with seed weight was first reported by Sax (1923). This association was confirmed by Nodari (1992) and Koinange et al. (1996) who reported that the phaseolin seed protein $(P h s)$ associated with seed weight was linked to the $P$ locus at $9 \mathrm{cM}$ on LG D7 in two genetic linkage maps. Johnson et al. (1996) found a consistent association between the Phs locus and seed weight across five different populations and noted that there was conservation of this association in at least one other legume species. However, Vallejos and Chase (1991) reported that while the $P h s$ locus was linked to the $P$ locus at $15.5 \mathrm{cM}$ on LG A, it was not associated with seed weight. In the present study, the SLR analysis indicated strong evidence of a QTL for seed weight linked to marker position AM13.425. The Phs locus has been mapped within the interval AM13.425-J09.750 (Freyre et al., 1998) nearer to AM13.425. Thus, our results are consistent with the detection of a QTL for seed weight near the Phs locus. A second QTL on LG 7 was also described by Koinange et al. (1996) in a region not covered by linkage map used in the present study. A fourth QTL for seed weight was found also by Koinange et al. (1996) on D11. It is not known which of the 11 LGs the markers on D11 belong to in the integrated bean linkage map (Freyre et al., 1998). However, all regions of the linkage map used in our study where we have found seed weight QTL correspond to regions of the map of Freyre et al. (1998) and Nodari et al. (1992), and none of these corresponds to LG D11. Thus, the seed weight QTL of Koinange et al. (1996) on D11 does not correspond to any of the QTL described herein.

Nodari (1992) found seed weight QTL on LGs D1, D3, D4, and D7 corresponding to the linkage groups B1, B3, B4, and B7 of Freyre et al. (1998). Of these QTL, those on LGs B1 and B7 correspond to QTL for seed weight also found by Johnson et al. (1996). The seed weight QTL on LG B3 linked to marker D1132 was located in a region of LG B3 not covered by the linkage map used in this study. The seed weight QTL on LG B4 described by Nodari (1992) was linked to marker D1011 which, based on examination of the integrated maps, appears to correspond to a position in the gap between linkage groups $4 \mathrm{a}$ and $4 \mathrm{~b}$ in our linkage map. However, we were unable to determine which linkage, $4 \mathrm{a}$ or $4 \mathrm{~b}$, is more closely related to the RFLP marker, D1011, used by Nodari (1992). Thus, either of the QTL found on LG4 could correspond to the QTL described previously by Nodari (1992).

Vallejos and Chase (1991) found a significant association between the isozyme locus $A d h 1$, and seed weight, length, and thickness. Seed thickness used by Vallejos and Chase (1991) is similar to seed height used herein. Vallejos et al. (1992) mapped Adhl to LG K which corresponds to B9 of the integrated map of Freyre et al. (1998). However, B9 is not represented in the linkage map developed for the 'PC-50' $\times$ XAN-159 population used in this study. Thus, we can conclude that no seed weight QTL described in the present report correspond to that previously described by Vallejos and Chase (1991).

Based on these results and those described above only the seed weight QTL on LG 7 and one of those found on LG 4 corresponded to a genomic region where a seed weight QTL has been 
described in a previous report. Thus, at least six of the eight candidate QTL reported herein for seed weight are unique to this study. Conversely, we found no QTL for seed weight in four genomic regions where seed weight QTL have been described previously. Taken together the results of Koinange et al. (1996), Nodari (1992), Vallejos and Chase (1991), and the present study indicate as many as 12 QTL for seed weight on bean LGs 1, 3, 4, $5,6,7,8$, and 9 .

Except for the QTL on LG 4a, which may have been reported as a QTL for seed weight by Nodari (1992), QTL described herein for seed height and length are unique to this report. Although seed height and length QTL co-occurred on LGs 4 and 11, they did not always occur in the same genomic regions which is consistent with the nonsignificant phenotypic correlation between the traits. The existence of independent QTL for each trait confirms that they can be manipulated independently in conventional or molecular breeding programs.

Other researchers identifying QTL associated with seed weight have used Andean x Mesoamerican crosses (Johnson et al., 1996; Koinange et al., 1996; Nodari, 1992; Vallejos and Chase, 1991). Large seeds are associated with Andean gene pool whereas small seeds are associated with Mesoamerican gene pool (Laing et al., 1984; Singh et al., 1991b). In the present study, two Andean parents were used. In addition, XAN-159 has genomic regions introgressed from $P$. acutifolius. Thus, the pedigrees of the lines used in this study would be expected to favor identification of unique variability for seed characteristics compared to previously studied materials.

In most cases, seed weight QTL were detected in the same genomic regions as seed height and seed length QTL. One exception occurred on LG 11 where the 'PC-50' allele had a negative effect on seed length but a positive effect on seed height. These opposite effects on the seed dimensions might be expected to cancel each other out resulting in no detectable effect on seed weight. In addition, there was one QTL for seed length on LG 2 where no QTL for seed weight was detected. Although in this case no seed height QTL were detected, it is possible that the 'PC-50' allele, which had a negative effect on seed length, has a positive effect on another component of seed weight at this locus. In general, 'PC-50' alleles were associated with larger seed weight and greater seed height. However, at three of the marker loci significantly associated with seed length, longer seed length was contributed by the XAN-159 allele.

All but one region significantly associated with resistance to CBB in leaves, based on the results of Jung et al. (1997), was linked to a QTL for seed weight, length or height (Fig. 2). Park et al. (1999) reported that the QTL for resistance to CBB was confirmed in a RIL backcross population and in an $\mathrm{F}_{2}$ population. Genes having a negative effect on seed size may have been introgressed with $\mathrm{CBB}$ resistance genes through linkage drag during the introgression of $\mathrm{CBB}$ resistance from a small seeded wild $P$. acutifolius accession in the development of XAN-159. The transfer of resistance genes derived from XAN-159 will require selection of recombinants with the resistance genes and the proper seed characteristics. However, if selection for resistance is to be based on molecular markers the linkage between seed weight QTL and CBB resistance QTL may result in recombinants carrying the resistance gene but having undesirable seed characteristics. If variation at the seed weight QTL detected herein occurs widely within $P$. vulgaris, than subsequent transfer of resistance genes between market classes with different seed types, such as pinto and navy, may be difficult as well. A more precise understanding of the relationship between resistance genes and seed size QTL will improve the predictability of molecular marker assisted transfer of resistance genes and lead to a better understanding of the results of conventional breeding as well.

\section{Literature Cited}

Al-Mukhtar, F.A. and D.P. Coyne. 1981. Inheritance and association of flower, ovule, seed, pod, and maturity characters in dry edible beans (Phaseolus vulgaris L.). J. Amer. Soc. Hort. Sci. 106:713-719.

Arnaud-Santana, E., D.P. Coyne, K.M. Eskridge, and A.K. Vidaver. 1994. Inheritance; low correlations of leaf, pod, and seed reactions to common blight disease in common beans; and implications for selection. J. Amer. Soc. Hort. Sci. 119:116-121.

Basten, C.J., B.S. Weir, and Z.B. Zeng. 1996. QTL cartographer: A reference manual and tutorial for QTL mapping. Dept. Stat., N.C. State Univ., Raleigh.

Bohn, M., M.M. Khairallah, D. Gonzalez-de-Leon, D.A. Hoisington, H.F. Utz, J.A. Deutsch, D.C. Jewell, J.A. Mihm, and A.E. Melchinger. 1996. QTL mapping in tropical maize: I. Genomic regions affecting leaf feeding resistance to sugarcane borer and other traits. Crop Sci. 36:1352-1361.

Bohn, M., M.M. Khairallah, C. Jiang, D. Gonzalez-de-Leon, D.A. Hoisington, H.F. Utz, J.A. Deutsch, D.C. Jewell, J.A. Mihm, and A.E. Melchinger. 1997. QTL mapping in tropical maize: II. Comparison of genomic regions for resistance to Diatraea spp. Crop Sci. 37:18921902.

Byrne, P.F., M.D. McMullen, B.R. Wiseman, M.E. Snook, T.A. Musket, J.M. Theuri, N.W. Widstrom, and E.H. Coe. 1998. Maize silk maysin concentration and corn earworm antibiosis: QTLs and genetic mechanisms. Crop Sci. 38:461-471.

Conti, L. 1982. Bean germplasm evaluation from the collection at Minoprio (Como, Italy) in view of a breeding program for the improvement of the protein content of the seed. Genetica Agraria 35:375-392.

Conti, L. 1985. Conclusive results of a selection program for obtaining a dwarf bean $(P$. vulgaris) resistant to some viruses and characterized by agronomical qualities. Genetica Agraria 39:51-63.

Coyne, D.P. 1968. Correlation, heritability, and selection of yield components in field beans, Phaseolus vulgaris L. Proc. Amer. Soc. Hort. Sci. 93:388-396.

Delaney, D.E. and F.A. Bliss. 1991. Selection for increased percentage phaseolin in common bean. I. Comparison of selection for seed protein alleles and S1 family recurrent selection. Theor. Appl. Genet. 81:301305.

Edwards, M.D., C.W. Stuber, and J.F. Wendell. 1987. Molecular markerfacilitated investigations of quantitative trait loci in maize. I. Numbers, genomic distribution, and types of gene action. Genetics 116:113-125.

Freyre, R., P.W. Skroch, V. Geffroy, A.F. Adam-Blondon, A. Shirmohamadali, W.C. Johnson, V. Llaca, R.O. Nodari, P.A. Pereira, S.M. Tsai, J. Tohme, M. Dron, J. Nienhuis, C.E. Vallejos, and P. Gepts. 1998. Towards an integrated linkage map of common bean. IV. Development of a core linkage map and alignment of RFLP maps. Theor. Appl. Genet. 97:847-856.

Hartana, A. 1983. Genetic variability on seed protein levels associated with two phaseolin protein types in common bean (Phaseolus vulgaris L.). MS thesis. Univ. Wis., Madison.

Johns, M.A., P.W. Skroch, J. Nienhuis, P. Hinrichsen, G. Bascur, and C. Munoz-Schick. 1997. Gene pool classification of common bean landraces from Chile based on RAPD and morphological data. Crop Sci. 37:605-613.

Johnson, W.C., C. Menendez, R. Nodari, E.M.K. Koinange, S. Magnusson, S.P. Singh, and P. Gepts. 1996. Association of a seed weight factor with the phaseolin seed storage protein locus across genotypes, environments and genomes in Phaseolus-Vigna spp.: Sax (1923) revisited. J. Quantitative Trait Loci 2: Article 5. http:// probe.nalusda.gov:8000/otherdocs/jqtl.

Jung, G., P.W. Skroch, D.P. Coyne, J. Nienhuis, E. Arnaud-Santana, 
H.M. Ariyarathne, S.M. Kaeppler, and M.J. Bassett. 1997. Molecularmarker-based genetic analysis of tepary bean-derived common bacterial blight resistance in different developmental stages of common bean. J. Amer. Soc. Hort. Sci. 122:329-337.

Jung, G., D.P. Coyne, J. Bokosi, J.R. Steadman, and J. Nienhuis. 1998. Mapping genes for specific and adult plant resistance to rust and abaxial leaf pubescence and their genetic relationships using randomly amplified polymorphic DNA (RAPD) markers in common bean. J. Amer. Soc. Hort. Sci. 123:859-863.

Koinange, E.M.K., S.P. Singh, and P. Gepts. 1996. Genetic control of the domestication syndrome in common bean. Crop Sci. 36:1037-1045.

Laing, D.R., P.G. Jones, and J.H.C. Davis. 1984. Common bean (Phaseolus vulgaris L.), p. 305-351. In: P.R. Goldsworthy and N.M. Fisher (ed.). The physiology of tropical field crops. Wiley, New York.

Lander, E.S., P. Green, J. Abrahamson, A. Barlow, M.J. Daly, S.E. Lincoln, and L. Newburg. 1987. MAPMAKER: An interactive computer package for constructing primary genetic linkage maps with experimental and natural populations. Genomics 1:174-181.

Mmbaga, M.T., J.R. Steadman, and J.R. Stavely. 1996. The use of host resistance in disease management of rust in common bean. Integrated Pest Mgt. Rev. 1:191-200.

Motto, M., G.P. Soressi, and F. Salamini. 1978. Seed size inheritance in a cross between wild and cultivated common beans (Phaseolus vulgaris L.). Genetica 49:31-36.

Nienhuis, J. and S.P. Singh. 1988. Genetics of seed yield and its components in common bean (Phaseolus vulgaris L.) of MiddleAmerican origin. II. Genetic variance, heritability and expected response from selection. Plant Breeding 101:155-163.

Nodari, R.O. 1992. Towards an integrated linkage map of common bean (Phaseolus vulgaris L.). PhD diss. Univ. Calif., Davis.

Pachico, D. 1989. Trends in common bean production, p. 1-8. In: H.F. Schwartz and M.A. Pastor-Corrales (eds.). Bean production problems in the tropics. Ctr. Intl. Agr. Trop., Cali, Colombia.

Park, S.O., D.P. Coyne, N. Mutlu, G. Jung, and J.R. Steadman. 1999. Confirmation of molecular markers and flower color associated with QTL for resistance to common bacterial blight in common beans. J. Amer. Soc. Hort. Sci. 124:519-526.

Ribaut, J.M., C. Jiang, D. Gonzalez-de-Leon, G.O. Edmeades, and D.A. Hoisington. 1997. Identification of quantitative trait loci under drought conditions in tropical maize. II. Yield components and marker-assisted selection strategies. Theor. Appl. Genet. 94:887-896.
Saladin, F., E. Arnaud-Santana, J.C. Nin, G. Godoy-Lutz, J.S. Beaver, D.P. Coyne, and J.R. Steadman. 2000. Registration of PC-50 red mottled dry bean. Crop Sci. (in press).

Sax, K. 1923. The association of size differences with seed coat pattern and pigmentation in Phaseolus vulgaris. Genetics 8:552-560.

Singh, S.P. 1991. Bean genetics, p. 199-286. In: A. van Schoonhoven and O. Voysest (eds.). Common beans: Research for crop improvement. CABI, Wallingford, U.K.

Singh, S.P., P. Gepts, and D.C. Debouck. 1991a. Races of common bean (Phaseolus vulgaris L., Fabaceae). Econ. Bot. 45:379-396.

Singh, S.P., J.A. Gutierrez, A. Molina, C. Urrea, and P. Gepts. 1991 b. Genetic diversity in cultivated common bean: II. Marker-based analysis of morphological and agronomic traits. Crop Sci. 31:23-29.

Skroch, P.W. 1998. Random amplified polymorphic DNA based germplasm and genetic mapping studies in common bean. $\mathrm{PhD}$ diss. Univ. Wis., Madison.

Thomas, C.V. and J.G. Waines. 1984. Fertile backcross and allotetraploid plants from crosses between tepary beans and common beans. Heredity 75:93-98.

Vallejos, C.E. and C.D. Chase. 1991. Linkage between isozyme markers and a locus affecting seed size in Phaseolus vulgaris L. Theor. Appl. Genet. 81:413-419.

Vallejos, C.E., J. Nienhuis, and P.W. Skroch. 1999. Phaseolus vulgaris. The common bean: Integration of RFLP and RAPD based linkage maps. In: R.L. Phillips and I.K. Vasil (eds.). DNA based markers in plants. Kluwer, Dordrecht, The Netherlands.

Vallejos, C.E., N.S. Sakiyama, and C.D. Chase. 1992. A molecular markerbased linkage map of Phaseolus vulgaris L. Genetics 131:733-740.

Veldboom, L.R. and M. Lee. 1996. Genetic mapping of quantitative trait loci in maize in stress and nonstress environments: I. Grain yield and yield components. Crop. Sci. 36:1310-1319.

White, J.W. and A. Gonzalez. 1990. Characterization of the negative association between seed yield and seed size among genotypes of common bean. Field Crops Res. 23:1-17.

White, J.W., S.P. Singh, C. Pino, M.J. Rios, and I. Buddenhagen. 1992. Effects of seed size and photoperiod response on crop growth and yield of common bean. Field Crops Res. 28:295-307.

Yarnell, S.H. 1965. Cytogenetics of the vegetable crops. IV. Legumes. Bot Rev. 31:247-330.

Zeng, Z.B. 1994. Precision mapping of quantitative trait loci. Genetics 136:1457-1468. 